\title{
APIS - A DIGITAL INVENTORY OF ARCHAEOLOGICAL HERITAGE BASED ON REMOTE SENSING DATA
}

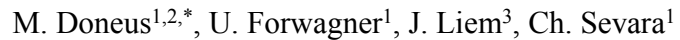 \\ ${ }^{1}$ IUHA - Department for Prehistoric and Historical Archaeology, University of Vienna, Franz Klein-Gasse 1, 1190-Vienna, Austria. \\ ${ }^{2}$ Ludwig Boltzmann Institute for Archaeological Prospection and Virtual Archaeology, Hohe Warte 38, 1190-Vienna, Austria. \\ ${ }^{3}$ Department of Computer Science, City - University of London, Northampton Square, London EC1V 0HB, United Kingdom.
}

Commission II

KEY WORDS: QGIS, Cultural Heritage, remote sensing, digital workflow, database, aerial archaeology, aerial photograph, archiving

\begin{abstract}
:
Heritage managers are in need of dynamic spatial inventories of archaeological and cultural heritage that provide them with multipurpose tools to interactively understand information about archaeological heritage within its landscape context. Specifically, linking site information with the respective non-invasive prospection data is of increasing importance as it allows for the assessment of inherent uncertainties related to the use and interpretation of remote sensing data by the educated and knowledgeable heritage manager. APIS, the archaeological prospection information system of the Aerial Archive of the University of Vienna, is specifically designed to meet these needs. It provides storage and easy access to all data concerning aerial photographs and archaeological sites through a single GIS-based application. Furthermore, APIS has been developed in an open source environment, which allows it to be freely distributed and modified. This combination in one single open source system facilitates an easy workflow for data management, interpretation, storage, and retrieval. APIS and a sample dataset will be released free of charge under creative commons license in near future.
\end{abstract}

\section{INTRODUCTION}

Archaeological heritage represents tangible objects and past traces of mankind, which enhance our knowledge of the past and have been investigated deliberately using archaeological methods. As part of cultural heritage, it is an important link between a society's past and present. Therefore, its protection is considered an imperative as expressed in the 1992 Valetta convention (Council of Europe 1992).

When it comes to the protection of archaeological heritage, one important practical problem is the fact that we can only protect what we know: without any information about their existence and extent, archaeological sites, objects and other remains cannot be protected. As the vast majority of our archaeological heritage is still undiscovered and buried in the subsoil, cultural heritage managers are, according to the Valetta treaty, in need of: (i) noninvasive methods to cost-effectively survey large areas in order to detect and document the existence and extent of archaeological heritage (ii) easy to use spatial inventories of archaeological heritage that allow us to understand archaeological heritage within its landscape context and that can be used in any kind of planning activity (Council of Europe 1992, Articles 2i, 3ib, 7i).

Today, non-invasive systematic surveys of large areas have been carried out in a growing diversity of environments (e.g. agricultural land, pastures, woodland, shallow water - Doneus and Briese, 2011; Gaffney et al., 2012; Trinks et al., 2012; Doneus et al., 2013a). These systematic surveys usually result in a large number of archaeological sites. However, large area inventories based on non-invasive prospection methods are usually subject to a varying degree of uncertainty. In addition, new prospection data may change a site's interpretation as well as its level of uncertainty (Figure 1). This has to be taken into account and needs to be reflected in any inventory of archaeological heritage.

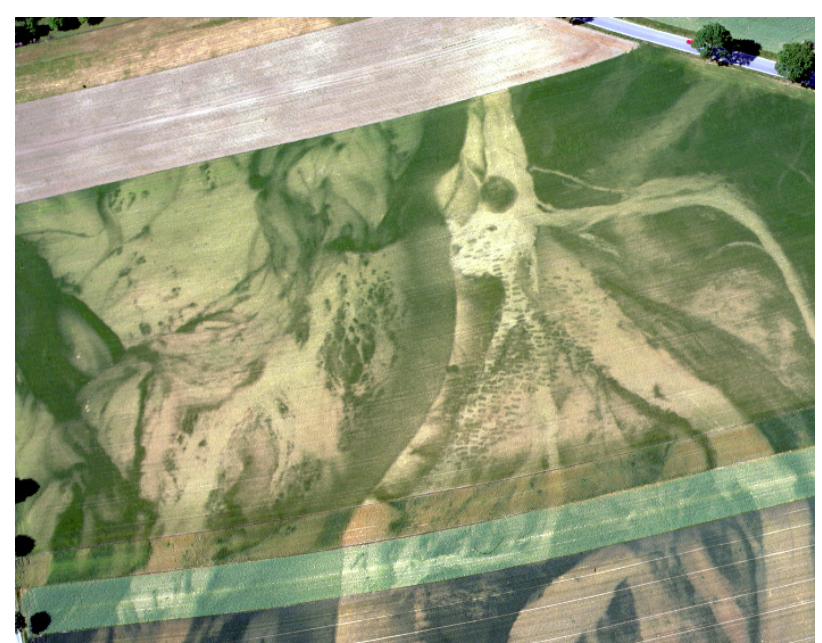

Figure 1: Vegetation marks hinting at a graveyard (right half, center) with more than 300 burials from the 8th century AD.

In an ideal case, a knowledgeable user should be able to review an interpretation and its level of uncertainty. Therefore, there seems to be a necessity for dynamic inventories, in which information on archaeological sites and their underlying source information (often aerial photographs or LiDAR-derived terrain models) can be retrieved in unison and which allow users to interactively change the extent and interpretation of archaeological information. Therefore, both prospection methods

\footnotetext{
* Corresponding author
} 
and spatial information about archaeological heritage need to be part of the information system.

APIS (archaeological prospection information system) was developed at the Aerial Archive of the University of Vienna specifically to meet these needs. It is a dynamic information system integrating information about archaeological heritage with the underlying source information from aerial photography and airborne laser scanning (ALS) remote sensing data. As such, APIS was specifically developed to allow for the smooth integration of archaeological prospection data into GIS-based digital workflows, including the use of semi-automated data capture and processing techniques to facilitate rapid data integration.

\section{APIS, A DYNAMIC HERITAGE DATABASE}

APIS is a dynamic, GIS-based information system designed to store and make accessible data concerning aerial photographs and archaeological sites. The current application has been developed from an initial database containing aerial photographs and archaeological sites from the aerial archive of the Department of Prehistoric and Historical Archaeology at the University of Vienna (Nikitsch, 1989). This database was restructured in Visual Foxpro during the late 1990s, and in the year 2000 a GISbased database was implemented in Arcview 3.3 (Doneus and Mayer, 2001). In order to further expand its functionality, it was redesigned in ArcGIS 10 in co-operation with the company SynerGIS (http://www.esri-austria.at - Doneus et al., 2013b). Finally, to allow for a broader use of the structure, it was reprogrammed and enhanced within the open source framework of QGIS. Along the way, a number of additional features were added, amongst them the possibility to allow world-wide input (previously the geographic extent of the database was confined to Austria) and to include information from different prospection methods such as field surveying.

\subsection{Concept}

APIS is a Python plugin developed for the free and open source geographic information system QGIS. Its functionalities integrate seamlessly into the QGIS user interface. Using custom classical dialogues, dynamic docking dialogues, and interactive map tools, an analyst can easily interact with the APIS specific data structure.

Currently, this structure is designed to handle vertical and oblique aerial photographs in combination with vector information indicating archaeological sites and their individual archaeological and palaeoenvironmental structures. The image data, including raw and compressed aerial photographs as well as orthophotos, are stored in a file-based structure. Additionaly, APIS implements a spatialite file geodatabase to incorporate the following inventory modules:

- Films (containing data about the production of the photographs, as date of flight, used cameras, lenses, films and formats)

- Flight paths (recorded during vertical and oblique reconnaissance flights as GPS tracks)

- Footprints of aerial photographs (spatial extent of each image)

- Archaeological sites (spatial extent and attributes)

- Archaeological sub-sites identified in site area (temporal placement, civilization, type, etc.)

- Mapped structures within sites and their interpretation

- A history log recording changes (add, edit, remove) In addition to data storage, three other areas can be distinguished when describing the entire system from a data perspective: data input, data handling, and data access (Figure 2). They are addressed in the next section, which describes the APIS user workflow.

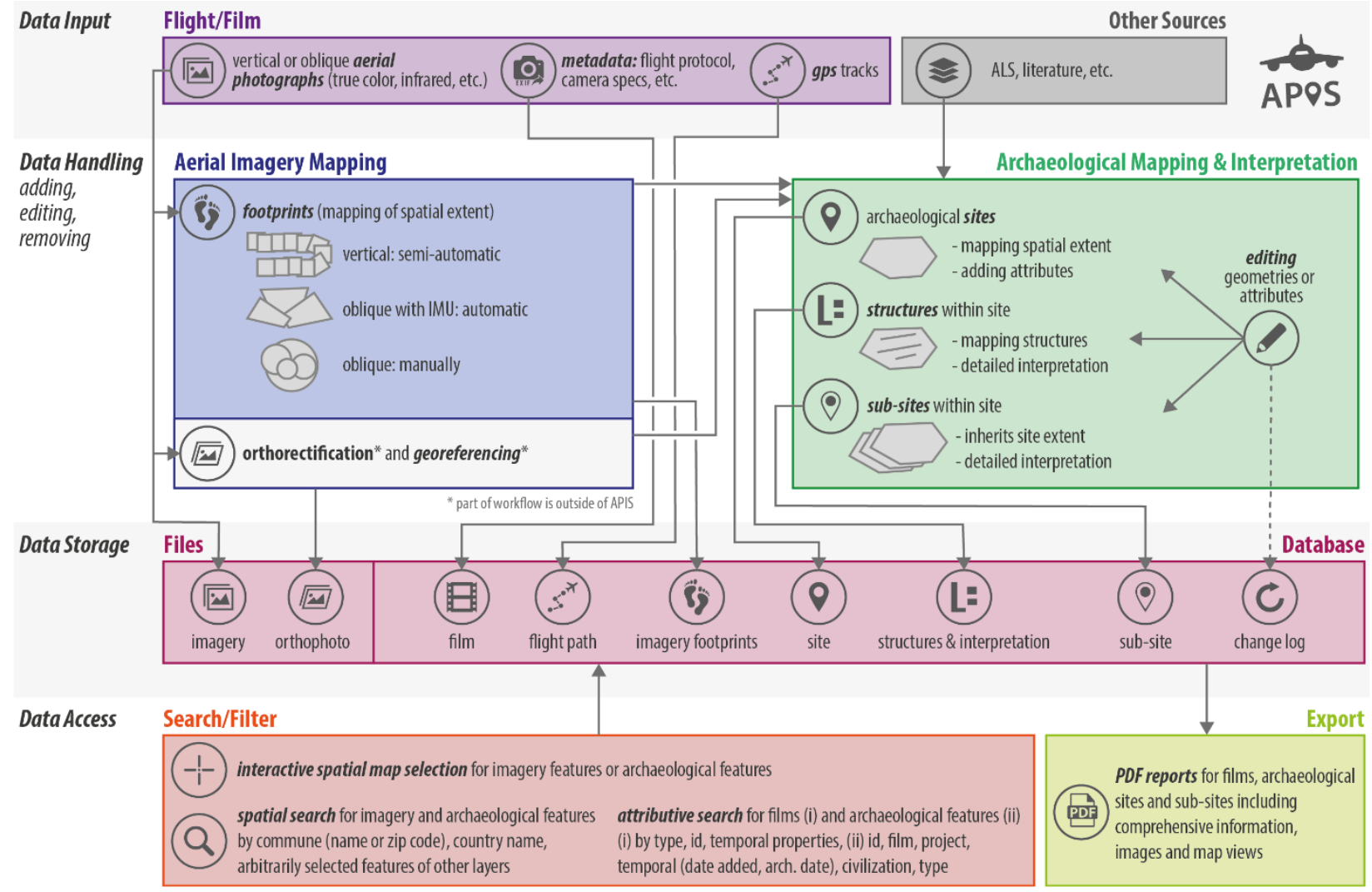

Figure 2: APIS concept 


\subsection{Workflow}

APIS is designed to incorporate all relevant data resulting from archaeological reconnaissance flights, including flight path data. During each reconnaissance flight, flight paths are tracked using handheld GPS devices. They provide important information because they record the flight path, including areas where no archaeological traces were recorded although reconnaissance had taken place. After a flight, an analyst prepares various data for the integration into the APIS archive. In addition to the aerial photographs, the analyst collects metadata about the flight (date, airports, pilot, duration, weather, etc.), the captured film (camera, lenses, film, format, camera operator) and the GPS flight track. This information is then interactively integrated into APIS. Custom interface modules in QGIS provide access to the stored data for the entire data handling process.

To simplify the next steps of mapping footprints as well as interpretative mapping of archaeological features (sites, structures, and palaeoenvironmental objects), analysts may load a background map (satellite map or topographical map), the relevant flight paths or any other helpful geographic data (e.g. orthophotographs) into QGIS to allow a better geographic orientation.

The footprints of the recorded aerial photographs are then generated and integrated into the archive. Depending on the type of photograph (vertical or oblique) different methods are used to map the spatial extent of each image. Vertical photographs are mapped in a semi-automated approach. First, each image center is manually defined by mouse input. Then the rectangular footprint of each photograph is algorithmically calculated for the entire film. For oblique image sequences, where an IMU (inertial measurement unit) was in place during the flight, the footprints are imported in a fully automatized way (Figure 3 ). If there is no georeferencing information available, the analyst manually maps the spatial extent of each image. The georeferencing and mapping of the footprints of all images, and their subsequent indexing, enables fast and easy access to all stored images.

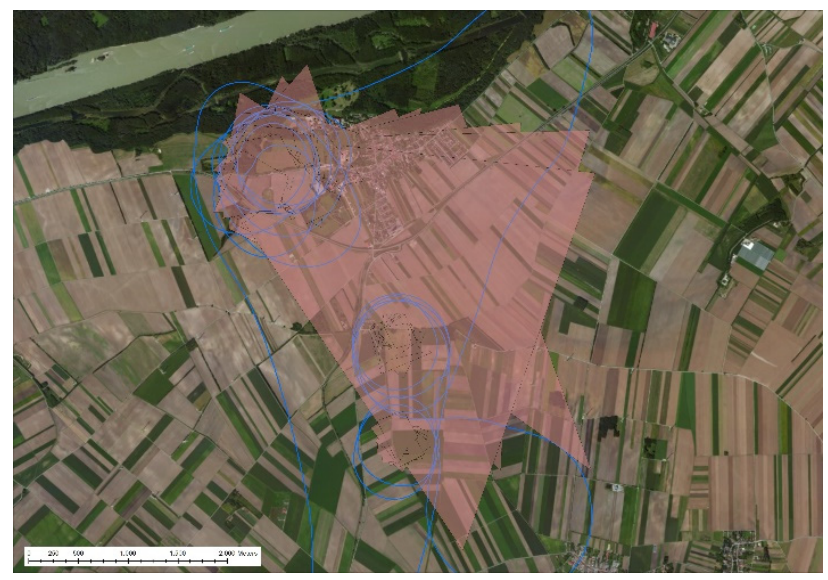

Figure 3. Fully automatized import of oblique photograph footprints based on IMU-measurements.
Within the aerial archaeological workflow, aerial photographs are rectified, georeferenced and stored as orthophotographs, which currently occurs outside the APIS workflow. Available orthophotos can then be retrieved and loaded into QGIS map canvas for further interpretation.

The oblique photographs, and also a considerable number of the verticals, show archaeological visibility marks on the ground that can be interpreted and mapped as archaeological structures. An area of interest covered by such archaeological features is referred to as a site. A site is therefore mainly a geographic location (Figure 4). It may contain various chronological/functional entities (e.g. a Neolithic settlement, an Iron Age cemetery, or Post-Medieval stray finds), which stratify the identified features in a temporal perspective or according to their type. For each of these functional-chronological entities, a "sub-site" is created, which is linked to the parent-site (see also Figures 4 and 5).

When identifying a site, its bounding polygon is mapped by visual interpretation of the captured aerial photographs. This polygon identifies the interpreted minimal extent of the site. In addition to the geometry, various site attributes have to be provided, including the degree of certainty, source of discovery, source for mapping site extent, and any additional information from other sources. For each site, a so-called representative image, which visually summarizes the archaeological situation, can be selected from the digital image repository or from any other location (e.g. ALS based relief shading, which is not part of the APIS data structure).

Identification of sub-sites is usually dependent on additional information. Sometimes, layout, orientation and size of vegetation marks hint at distinct site types (in Austria e.g. Middle Neolithic Kreisgrabenanlagen, Roman villas). However, it is additional information from field walking, literature or other prospection techniques that helps to determine sub-sites (Figure 4). Each mapped sub-site feature will receive its own attributes (information on chronology, archaeological culture, type of site, degree of (un-)certainty).

In the event that new evidence arises from any of the sources described above, APIS also offers editing tools to alter and adopt geometries and attributes of the archaeological features. When changing geometries, APIS performs typology checks and automatically extends or shrinks dependent geometries. Any changes (adding, editing, removing) of archaeological features are logged in a history table in the database,providing a record of feature development over time.

APIS also offers numerous ways to access the data and display geometries in the QGIS map canvas or within the customized dialogues. A map tool for spatial selection enables users to interactively search for imagery (Figuer 5), sites (Figure 6), and palaeoenvironments by drawing a rectangle (or clicking) on the map canvas. Additionally, cadastral commune names or numbers, country names or any arbitrarily selected features (of any loaded layers) provide spatial search options for the same feature groups. An attributive search lets users look up films by dates and film numbers. Archaeological features (sites and palaeoenvironments) can be queried by site number, film number, project name, chronology, culture, type, and more. 


\section{Example Workflow}

Aerial Imagery Mapping,

Archaeological Mapping \& Interpretation

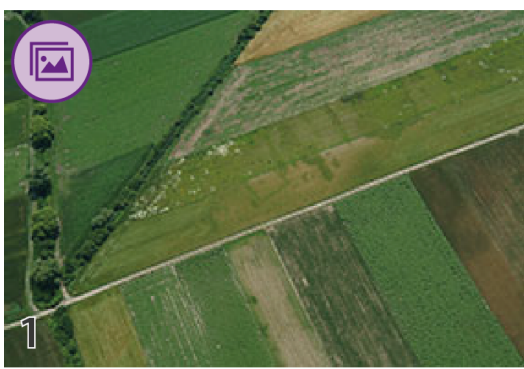

1 | aerial photograph (one out of many of a film)

$2 \mid$ derived orthophoto and mapped footprint (spatial extent)

3 | interactively mapping site geometry (extent) and adding attributes (certainty, sources, etc.)

4 mapping structures and adding detailed interpretations

$5 \mid$ adding functional-chronological entities (sub-sites) (certainty, civilization, age determination, type, etc.)

2 - 5 | satellite background map
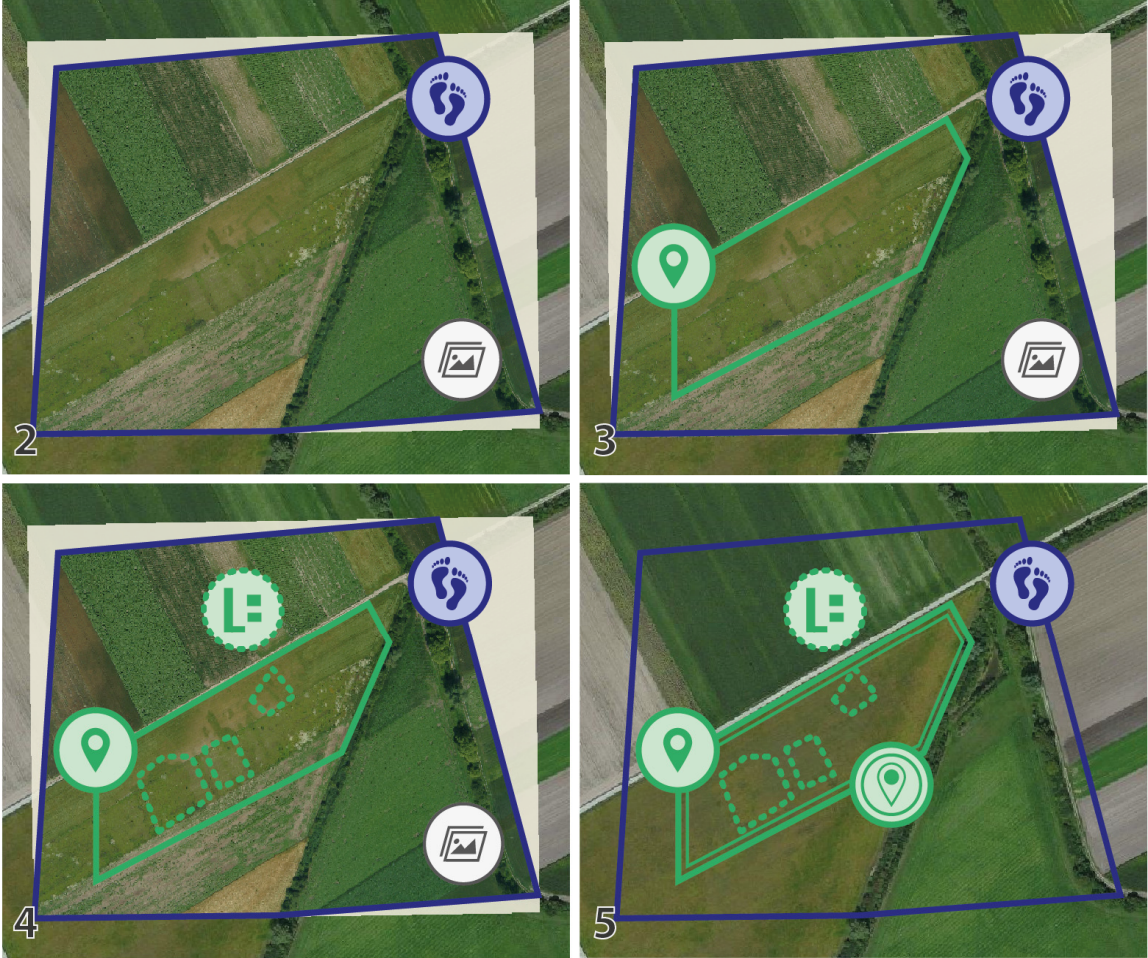

Figure 4: APIS example workflow for aerial imagery mapping and archaeological mapping and interpretation.

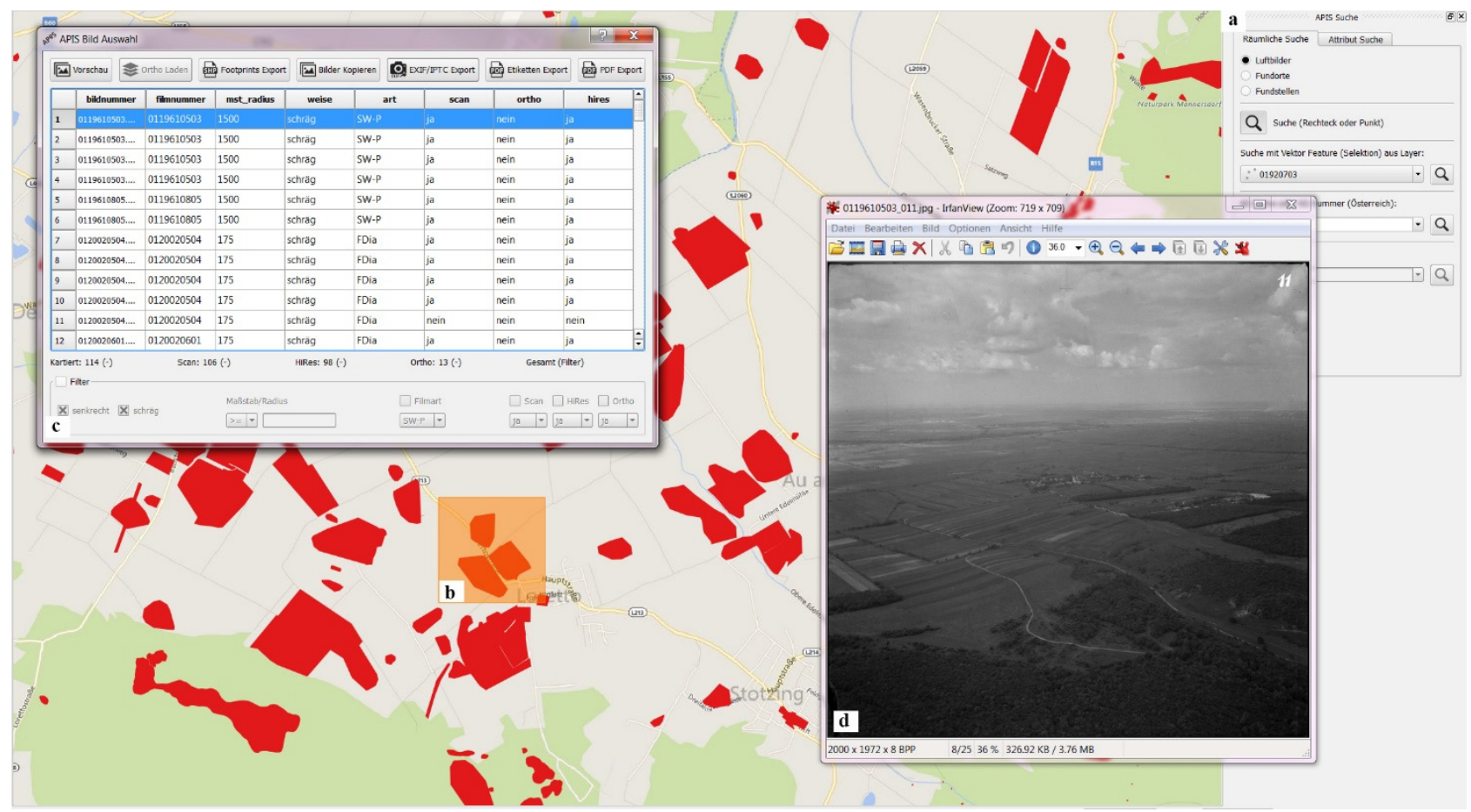

Figure 5: APIS: search procedure for aerial photographs. (a) filter (b) search polygon (c) list of aerial photographs within polygon area (d) scanned aerial photograph pops up when the respective entry from the list was double-clicked. Red polygons in the background delineate archaeological sites. 


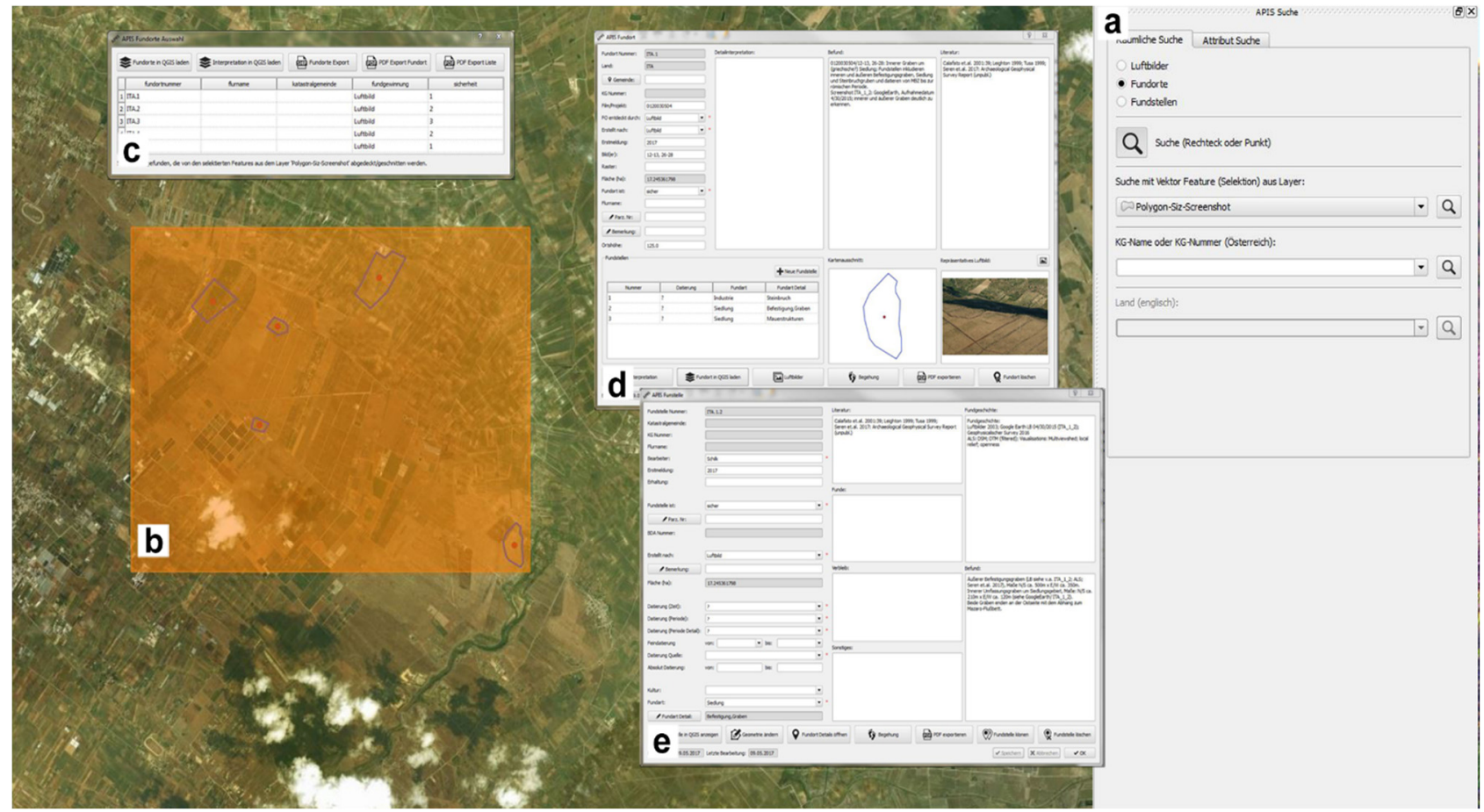

Figure 6: APIS: search procedure for archaeological sites in Sicily. (a) filter (b) search polygon(c) list of sites within polygon area (d) information window for a selected site (e) detailed information on sub-site.

A considerable number of the archaeological and structures visible in aerial images have been interpreted and mapped as single features stored in shapefiles of the respective site (Figure 7). These detailed archaeological interpretations can automatically be loaded into QGIS map canvas and easily be accessed via the site dialogue or the APIS search tool. Having different kinds of topographical and thematic (geological, pedological, satellite images) maps in the background, site distributions can be interactively investigated. Palaeoenvironmental features mapped from aerial photographs (Figuer 7) are stored in an extra shapefile. GPS-recorded flight paths, surveying information and any other kind of mapped data can be automatically loaded and visualised if required.

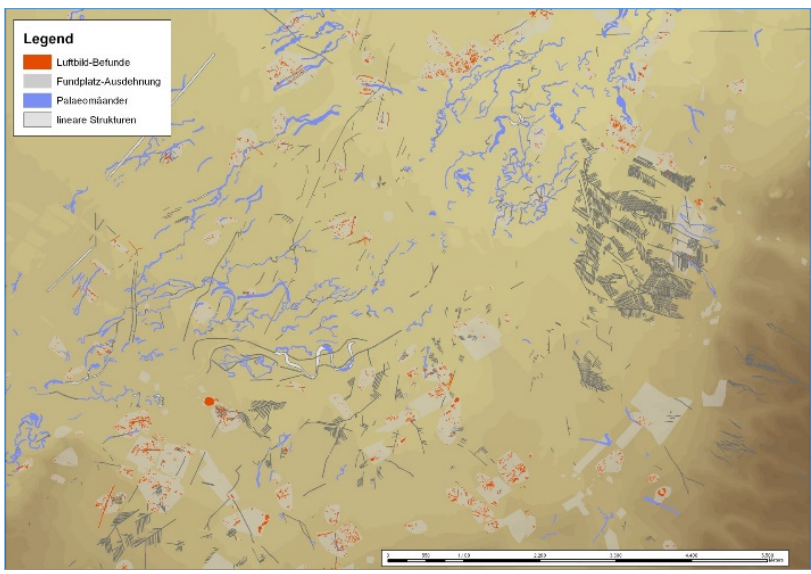

Figure 7: Map of all archaeological and palaeoenvironmental structures, stored as shapefiles of the respective site and automatically loaded into the GIS environment by APIS.
APIS also provides a wide range of reporting and data interoperability tools. For example, PDF reports for films, archaeological sites and sub-sites can be exported. These include comprehensive information, images and map views. Additionally, shapefiles of selected sites can be exported for use in other spatial applications, and selected images can be copied to external storage media.

\subsection{APIS in use: the aerial archive}

Currently, the main function of the database is to administrate the inventory of the aerial archive at the Department for Prehistoric and Historical Archaeology at the University of Vienna. Founded in 1961, the archive has since grown constantly, with input of vertical and oblique aerial photographs and archaeological sites derived from air photo interpretation and external sources over various countries (especially Austria and Italy/Sicily). At the moment, it comprises more than 120,000 oblique and vertical aerial photographs, the latter being on permanent loan from the Austrian Armed Forces (Bohly, 1982). If not acquired digitally, the aerial photographs are scanned with the Vexcel Ultra Scan 5000. Using its automatic roll film unit, a complete film is scanned image by image automatically at a resolution of 15 microns (Gruber and Leberl, 2001). Currently, all analogue oblique photographs have been scanned, as well as 60.000 of the vertical photographs (ca. 70\%) adding up to several terabytes of hard-disk space. To facilitate long term storage, digital images are stored both in raw and jpg format. Scanned material is compressed using MrSID algorithm. All data are automatically copied on a regular basis to a server, which is located in a different part of Vienna. From there, it is again automatically copied to tape drives at regular intervals.

APIS is used on a daily basis, where new aerial photographs are imported either automatically (if they were photographed using 
GPS and IMU - Figure 3; see also Doneus et al. 2016) or manually. So far, APIS contains more than 6,400 archaeological sites from Austria and other European project areas (e.g. Doneus, 2006) more than half of them detected through aerial reconnaissance. The chronology of the sites ranges from prehistoric times up to the present. Interpretation and reinterpretation of aerial photographs also takes place on a regular basis, mainly in connection with specific regional projects. Most frequently, queries for sites within a specific area or aerial photographs covering specific sites or regions are performed. This is usually completed within minutes, including automated copying of the resulting data and digital images to be used in subsequent aerial archaeology workflows.

\section{DISCUSSION}

If archaeological site information has to be retrieved on a large, country-wide scale, aerial archaeology and airborne laser scanning can provide vital large area, high-resolution data that support this goal. Therefore, APIS is primarily designed to incorporate information from aerial photographs and link them with archaeological site information. This is important, as today, hundred millions of aerial photographs are stored in a large number of archives worldwide and it is crucial for us to be able to locate and retrieve relevant images as quickly as possible. This is only possible if the aerial photographs are archived in a systematic way that is easy to understand and allows us to perform even complex queries and to access the photographs found in a short time. Using GIS, easy-to-use environments can be created and even made available over the World Wide Web. APIS provides a GUI to easily import metadata and footprints of aerial photographs and to link this information with the respective digital datasets of the photographs. As a result, georeferenced aerial photographs and archaeological sites can be quickly found within an interactive GIS interface simply by drawing a polygon on a map.

From a heritage management perspective, it seems to be important that APIS provides a dynamic database in which aerial photographs and archaeological sites are automatically linked by geographic location. Newly acquired photographs can be interactively interpreted and compared with the current archaeological site information. Obversely, information about archaeological sites can be checked against available aerial photographic evidence. In that way, new information (e.g. additional features, re-interpretation of functional and/or temporal information, or changing a site's boundary polygon) can be quickly incorporated into the archaeological site record. As the site information usually comes from an interpretation of remote sensing data, the resulting inventory will incorporate various degrees of certainty. This is accounted for in the database, where the degree of certainty has to be specified for each site. Again, having new information at hand, the degree of certainty can be changed, if necessary.

APIS is only part of the aerial archive's aerial archaeological workflow and as such is integrated with and has interfaces to other, recently developed soft- and hardware packages. It can directly import geo-referencing information that comes from our recently developed IMU system for oblique aerial cameras (Doneus et al., 2016). In that way, automated archiving of oblique aerial photographs, including their footprints and transformed (however, at this stage not orthorectified) images, has become possible. On the other side of the workflow, selected photographs can be fed into OrientAL, a software package which to a certain degree automatizes the creation of true orthophotographs from a bundle of oblique and vertical aerial photographs (Karel et al., 2013; Karel et al., 2014).

Being programmed within an open source framework, APIS and a sample dataset will be released free of charge under creative commons license in near future. At that time, we hope to have also developed a better integration into an interpretative mapping environment. Additionally, we would like to incorporate the management of metadata from other prospection techniques (mainly ALS and geophysical prospection). Finally, while datasets of all of the mentioned techniques can be loaded as background information into the GIS environment, a systematic way to integrate metadata and search functions directly into the APIS database would be a helpful enhancement to the workflow.

\section{CONCLUISON}

The archaeological prospection information system (APIS) is a dynamic GIS-based information system using the freely available QGIS platform. It is designed to store and allow easy access to all data concerning aerial photographs and archaeological sites. This combination in one single system facilitates an easy workflow based on aerial archaeological research, and provides an overview of all available archaeological information for a given area.

One of its biggest merits is the fact that APIS allows us to interactively relate to archaeological heritage within its landscape context, linking site information with the respective non-invasive prospection data and any other geographical information source within a GIS. This is of importance as it helps with the assessment of inherent uncertainties related to the use and interpretation of remote sensing data by heritage managers.

Therefore, APIS provides an open, up-to-date, straightforward, and user-friendly application for research and cultural heritage management projects of all scales.

\section{ACKNOWLEDGEMENTS}

Part of this research was carried out with the financial support of the Austrian Science Fund (FWF): P28410-G25.

The Ludwig Boltzmann Institute for Archaeological Prospection and Virtual Archaeology (archpro.lbg.ac.at) is based on an international cooperation of the Ludwig Boltzmann Gesellschaft (A), the University of Vienna (A), the Vienna University of Technology (A), ZAMG-the Austrian Central Institute for Meteorology and Geodynamics (A), the Province of Lower Austria (A), Airborne Technologies (A), 7reasons (A), the Austrian Academy of Sciences (A), the Austrian Archaeological Institute (A), RGZM-the Roman-Germanic Central Museum Mainz (D), the National Historical Museums - Contract Archaeology Service (S), the University of Birmingham (GB), the Vestfold County Council (N) and NIKU-the Norwegian Institute for Cultural Heritage Research (N).

\section{RFERENCES}

Bohly, W.D., 1982. Die Fliegerkompanie. In: Windl, H. (Ed.), Fenster zur Urzeit. Luftbildarchäologie in Niederösterreich, Asparn, pp. 9-16.

Council of Europe, 1992. Treaty No.143, European Convention on the Protection of the Archaeological Heritage (revised).

Doneus, M., 2006. Aerial archaeology in the area of Mazara del Valo, Sicily. Report of reconnaisance seasons 2003 and 2004. Archaeologia Aerea, II, 2006: 269-284. 
Doneus, M., Briese, C., 2011. Airborne Laser Scanning in Forested Areas - Potential and Limitations of an Archaeological Prospection Technique. In: Cowley, D. (Ed.), 2010. Remote Sensing for Archaeological Heritage Management. Proceedings of the $11^{\text {th }}$ EAC Heritage Management Symposium, Reykjavik, Iceland, 25-27 March 2010. Archaeolingua; EAC, Budapest, pp. 53-76.

Doneus, M., Doneus, N., Briese, C., Pregesbauer, M., Mandlburger, G., Verhoeven, G., 2013a. Airborne Laser Bathymetry - detecting and recording submerged archaeological sites from the air. Journal of Archaeological Science 40, 2136-2151.

Doneus, M., Fornwagner, U., Kiedl, C., 2013b. APIS Archaeological Prospection Information System. In: Neubauer, W., Trinks, I., Salisbury, R.B., Einwögerer, C. (Eds.), Archaeological Prospection. Proceedings of the $10^{\text {th }}$ International Conference - Vienna. Verl. der Österr. Akad. d. Wiss., Wien, pp. 317-318.

Doneus, M., Mayer, C., 2001. GIS-based archiving of aerial photographs and archaeological sites. In: Doneus, M., Neubauer, W., Eder-Hinterleitner, A. (Eds.), 2001. Archaeological prospection: Fourth International Conference on Archaeological Prospection, Vienna, 19-23 September 2001. VÖAW, Wien, pp. 89-91.

Doneus, M., Wieser, M., Verhoeven, G., Karel, W., Fera, M., Pfeifer, N., 2016. Automated Archiving of Archaeological Aerial Images. Remote Sensing 8 (3), 209.

Gaffney, C., Gaffney, V., Neubauer, W., Baldwin, E., Chapman, H., Garwood, P., Moulden, H., Sparrow, T., Bates, R., Löcker, K., Hinterleitner, A., Trinks, I., Nau, E., Zitz, T., Floery, S., Verhoeven, G., Doneus, M., 2012. The stonehenge hidden landscapes project. Archaeological Prospection 19 (1), 147-155.

Gruber, M., Leberl, F., 2001. Description and evaluation of the high quality photogrammetric scanner UltraScan 5000. ISPRS Journal of Photogrammetry and Remote Sensing 55, 313-329.

Karel, W., Doneus, M., Briese, C., Verhoeven, G., Pfeifer, N., 2014. Investigation on the Automatic Geo-Referencing of Archaeological UAV Photographs by Correlation with PreExisting Ortho-Photos. In: Remondino, F., Menna, F. (Eds.), ISPRS Technical Commission V Symposium, 23-25 June 2014, pp. 307-312.

Karel, W., Doneus, M., Verhoeven, G., Briese, C., Ressl, C., Pfeifer, N., 2013. Oriental - automatic geo-referencing and ortho-rectification of archaeological aerial photographs. In: Grussenmeyer, P. (Ed.), XXIV International CIPA Symposium 02-06 September 2013, Strasbourg, France. Copernicus Publications, Göttingen, pp. 175-180.

Nikitsch, R., 1989. Die archäologische Datenbank „MUFDARCH“. Archaeologia Austriaca 73, 1-12.

Valletta, 1992. Treaty No.143, European Convention on the Protection of the Archaeological Heritage (revised).

Trinks, I., Neubauer, W., Doneus, M., 2012. Prospecting Archaeological Landscapes. In: Ioannides, M., Fritsch, D., Leissner, J., Davies, R., Remondino, F., Caffo, R. (Eds.), Progress in Cultural Heritage Preservation. $4^{\text {th }}$ International Conference, EuroMed 2012, Limassol, Cyprus, October 29 - November 3, 2012. Proceedings. Springer, Berlin, Heidelberg, pp. 21-29. 